NOTE

\title{
Molecular Motion in Poly(amino acid). IV. Molecular Motion in $\alpha$-Form Silk Fibroin
}

\author{
Masanobu NAGURA and Hiroshi ISHIKAWA \\ Faculty of Textile Science and Technology, Shinshu University, \\ Ueda 386, Japan.
}

(Received May 21, 1979)

\begin{abstract}
KEY WORDS Molecular Motion / $\alpha$-Form Silk Fibroin / Hydrogen Bonds / Crystal / Amorphous / Degradation / X-Ray / Tan $\delta$ /
\end{abstract}

In preceding papers, ${ }^{1,2}$ molecular motions in the $\beta$-form of silk fiber crystals of Bombyx mori and Tusser, and in poly(L-alanine) fibers, whose molecular chains form antiparallel chain pleatedsheets with the intermolecular hydrogen bonds, have been studied by the X-ray diffractomtric method. It is considered that the molecular chains having intermolecular hydrogen bonds begin to undergo molecular motion, which is different from the thermal molecular vibration in the crystal lattice above $160^{\circ} \mathrm{C}$.

The analysis of the crystal structure of the $\alpha$-form of silk fibroin of Bombyx mori has been studied by Hirabayashi et al. ${ }^{3,4}$ and Konishi et al..$^{5}$ According to them, the crystal is orthorhombic. The results of both groups coincided with each other with respect to the lattice constants and the Miller indices perpendicular to the molecular axis, while with respect to the lattice constants parallel to the molecular axis, the results of both groups did not agree with each other. It is noteworthy that the crystal is constituted by helical molecular chains connected side by side with intermolecular hydrogen bonds rather than intramolecular bonds in the ordinary $\alpha$-helical molecule of the poly(amino acid).

In this paper, the molecular motion in the crystal of $\alpha$-form silk fibroin was investigated and comparison was made with the molecular motion in the $\beta$-form of poly(amino acid) crystals. ${ }^{1}$ Also, a study was made of the manner in which is related to its degradation. The molecular motion in the amorphous parts of the $\alpha$-form silk fibroin could be elucidated for a brief period by a differential scanning calorimeter.

\section{EXPERIMENTALS}

The middle division of the degummed silk gland in the full-grown larva of Bombyx mori was compressed to a thickness of about $1 \mathrm{~mm}$ on the polyethylene film and dried at room temperature. Then the film was dried in vacuo at $180^{\circ} \mathrm{C}$ for $30 \mathrm{~min}$. As a result, a typical X-ray pattern of the $\alpha$-form of silk fibroin could be seen.

The dynamic mechanical loss tangent $(\tan \delta)$ was measured by a dynamic viscoelastometer (Rheovibron DDV-II type, Toyo Boldwin Co., Ltd.) at a frequency of $110 \mathrm{~Hz}$ and at a heating rate of about $2^{\circ} \mathrm{C} \mathrm{min}^{-1}$ in a $\mathrm{N}_{2}$ gas atmosphere.

The X-ray diffractometric measurement was performed by a diffractometer (Rigaku Denki Co., Ltd.) with a scintillation counter and a pulse height analyser, using $\mathrm{Cu}-\mathrm{K} \alpha$ radiation. The diffraction intensity curves were measured at a scanning rate of 0.25 degree $\min ^{-1}$, with a full scale of $2000 \mathrm{cps}$ and at a time constant of $2 \mathrm{~s}$. The temperature was controlled by a temperature regulator made by Takara Kogyo Co., Ltd., with a control accuracy of $\pm 0.5^{\circ} \mathrm{C}$ in a $\mathrm{N}_{2}$ gas atmosphere.

The thermal properties were investigated by a differential scanning calorimeter (DSC), a thermogravity analyser (TGA) and a thermo-mechanical analyser (TMA) at a heating rate of $2.5^{\circ} \mathrm{C} \mathrm{min}^{-1}$ in a $\mathrm{N}_{2}$ gas atmosphere.

\section{RESULTS AND DISCUSSION}

\section{Molecular Motion in a Crystal}

The temperature dependence of $\tan \delta$ is shown in 
Figure 1. With increasing temperature the $\tan \delta$ shows a sharp increase above about $160^{\circ} \mathrm{C}$, a shoulder at about $205^{\circ} \mathrm{C}$ and an increase again above about $220^{\circ} \mathrm{C}$. These phenomena were given the following assignments by $\mathrm{X}$-ray and thermal measurement.

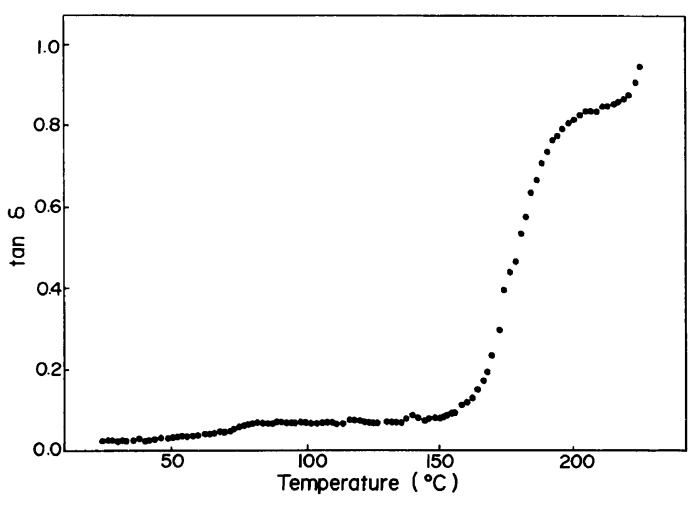

Figure 1. Temperature dependence of $\tan \delta$.

The temperature dependence of the spacings of $(100)$ and $(010), d_{100}$ and $d_{010}$, are shown in Figure 2.

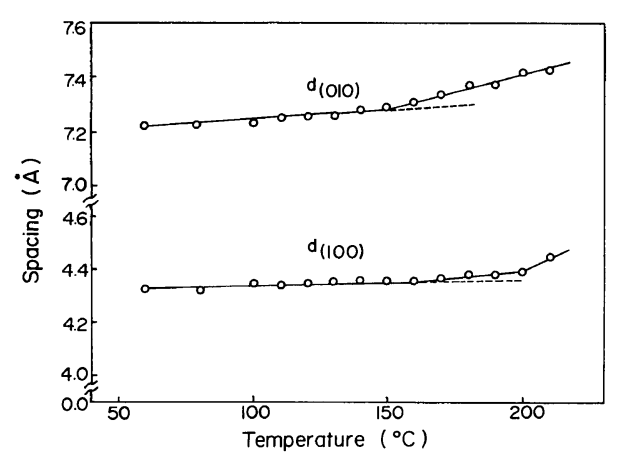

Figure 2. Temperature dependences of the spacings for 100 and 010 reflection.

The slope of the spacing $v s$. the temperature curve in the figure gives the thermal expansion coefficient, $\alpha$. The $\alpha_{100}$ for $d_{100}$ corresponding to the periodicity between the helical molecules with intermolecular hydrogen bonds is $4.2 \times 10^{-5} \mathrm{deg}^{-1}$ below $160^{\circ} \mathrm{C}$, and the $\alpha$ values calculated from Figure 2 in the ref 8 for the $\beta$-form crystal of poly ( $\gamma$-methyl D-glutamate), PMDG, and Figure 9 in the ref 5 for the $\beta$-form crystal of poly(L-alanine), PLA, were $5.2 \times 10^{-5}$ $\mathrm{deg}^{-1}$ and $3.5 \times 10^{-5} \mathrm{deg}^{-1}$, respectively. Thus, the expansion coefficient of the crystal lattice of the $\alpha$ form of silk fibroin agrees with that of the $\beta$-form crystal for PMDG and PLA. On the other hand, the $\alpha_{010}$ for $d_{010}$, corresponding to the periodicity perpendicular to the intermolecular hydrogen bonds between the helical molecular chain, is larger than $\alpha_{100}$ and it is $9.2 \times 10^{-5} \mathrm{deg}^{-1}$ below $160^{\circ} \mathrm{C}$. These results show that the intermolecular force is anisotropic in the crystal. Therefore, the helical molecules in the crystals of $\alpha$-form silk fibroin also form molecular sheets by intermolecular hydrogen bonds just as does the $\beta$-form; the intersheet force is weaker than the intermolecular hydrogen bonding force in the sheets. Consequently, a larger value of $\alpha_{010}$ is attributed to the active motion of the side chain in the intersheet as described by Matsushima et al. ${ }^{8}$

As shown in Figure 2, $d_{100}$ and $d_{010}$ gradually increase above $160^{\circ} \mathrm{C}$. This means that the molecular chains begin to undergo molecular motion in the crystals of the $\alpha$-form silk fibroin above $160^{\circ} \mathrm{C}$. Since the $\tan \delta$ curve shows a dispersion above about $160^{\circ} \mathrm{C}$, this dispersion may be due to the molecular motion in the crystal of the $\alpha$-form silk fibroin. As shown in Figure 3A, the TMA curve under the small load shows two stages of elongation: gradually above $154^{\circ} \mathrm{C}$ and remarkably above $210^{\circ} \mathrm{C}$. The first stage of the elongation corresponds to the temperature region of the increase of the spacing as shown in Figure 2. This supports the existence of molecular motion in the crystal as described above. The temperature at the onset of the molecular motion is similar to that of the $\beta$-form silk fibroin ${ }^{1}$ and that of the $\beta$-form PLA. These results suggest that molecular motion generally occurs above about $160^{\circ} \mathrm{C}$ in crystals of poly(amino acid)s having the intermolecular hydrogen bonds. According to Kajiyama ${ }^{6,7} \alpha$-helical molecules with intramolecular hydrogen bonds such as PMLG start undergoing motion parallel to the molecular axis, i.e., the intermolecular slip-motion above $140^{\circ} \mathrm{C}$ and the accordion-motion in each helical molecule above about $180^{\circ} \mathrm{C}$ with decreasing hydrogen bonding force. In the future, it should be worth to find out whether such a type of molecular motion occurs also in helical molecules having the intermolecular hydrogen bonds mentioned in this study.

The second stage of the elongation on the TMA 


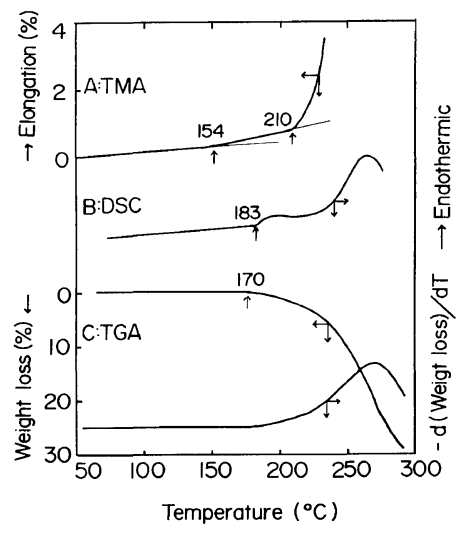

Figure 3. TMA, DSC, and TGA thermograms.

curve nearly agrees with the temperature of the disappearance of the reflection peaks on the X-ray diffraction intensity curve and the temperature at which the $\tan \delta$ value increases again. Although a crystallinity of $18.7 \%$ was obtained from Hermann's method, the DSC thermogram (see Figure 3B) does not show any endothermic peak with respect to the melting at the temperature of the disappearance of the reflection peaks on the $\mathrm{X}$-ray diffraction intensity curve. These results mean that the crystal of the $\alpha$ form silk fibroin does not melt at about $210^{\circ} \mathrm{C}$, but that the crystal may be disordered by the large scale of molecular motion, thus becoming soft enough to elongate.

\section{Glass Transition and Degradation}

The DSC curve shows the shift to the endothermic side above $183^{\circ} \mathrm{C}$ as shown in Figure 3B. The glass transition temperature was determined by a dilatometer ${ }^{1}$ and $\mathrm{DSC}^{9}$ for the amorphous regenerated silk fibroin cast film, to be $175^{\circ} \mathrm{C}$. Thus, the shift of the DSC curve to the endothermic side is due to the glass transition of the amorphous parts in the $\alpha$-form silk fibroin. The shoulder on the $\tan \delta$ curve at $205^{\circ} \mathrm{C}$ shown in Figure 1 is attributed to the superposition of the glass transition at $183^{\circ} \mathrm{C}$ on the molecular motion in the crystal which gradually occurs above $160^{\circ} \mathrm{C}$ and remarkably above $210^{\circ} \mathrm{C}$ as described above.

Figure 3C shows the TGA thermogram. The weight loss appears above $170^{\circ} \mathrm{C}$. When the $\alpha$-form silk fibroin was cooled from $220^{\circ} \mathrm{C}$ to $25^{\circ} \mathrm{C}$, the reflection peaks reappeared and showed almost the same intensity at the reflection angle of the initial crystal of the $\alpha$-form silk fibroin. Therefore it is considered that below $220^{\circ} \mathrm{C}$, the molecular chains in the crystal phase do not degradate, but that the molecular chain-ends and/or side groups of the molecular chains in the amorphous phase do degradate.

A peak appears at $270^{\circ} \mathrm{C}$ on the first differential curve of the weight loss $v s$. temperature plot. The ordinate indicates the degradation rate, since the temperature is raised linearly with time. This peak temperature agrees with the peak temperature on the DSC thermogram. These results mean that the degradation of the main chain may occur chiefly at about $270^{\circ} \mathrm{C}$.

Acknowledgment. The authors wish to thank Mr. K. Kojima and Miss. T. Shigeno for their cooperation in these experiments.

\section{REFERENCES}

1. M. Nagura, K. Goto, and H. Ishikawa, Kobunshi Ronbunshu, 34, 389 (1977).

2. M. Nagura, M. Urushidani, H. Shinohara, and H. Ishikawa, Kobunshi Ronbunshu, 35, 81 (1978).

3. K. Hirabayashi, H. Ishikawa, M. Kakudo, and Y. Go, Sen-i Gakkaishi, 24, 392 (1968).

4. K. Hirabayashi, H. Ishikawa, M. Kakudo, and Y. Go, Sen-i Gakkaishi, 24, 397 (1968).

5. T. Konishi and M. Kurokawa, Sen-i Gakkaishi, 24, 550 (1968).

6. T. Kajiyama, M. Kuroishi, and M. Takayanagi, Chemistry Letters, 659 (1973).

7. T. Kajiyama, M. Kuroishi, and M. Takayanagi, $J$. Macromol. Sci-phys., B11, 121 (1975).

8. N. Matsushima and K. Hikichi, Polym. J., 9, 391 (1977).

9. J. Magoshi and S. Nakamura, J. Appl. Polym. Sci., 19, 1013 (1975). 